\title{
Challenges in Globalisation of Global Software Development: A Conceptual Study of Co-locating Key Roles and its Impact on Product Life Cycle
}

\author{
Umasankar Saketharaman* and Victor Anandkumar ${ }^{\dagger}$
}

\begin{abstract}
This study characterises the results of published scientific research in the field of Global Software Product Development (GSD). Based on the analysis of about 22 scholarly articles published between 2001 and 2014, it is observed that in spite of issues and challenges faced in its implementation, GSD is a business necessity. To ensure more successful realisation of the benefits of GSD, colocating some of the key-roles at global locations along with software development could be exercised. This could have a positive impact on the software product life cycle. This relationship needs to be validated by further research backed with empirical data.
\end{abstract}

Keywords: Global Software Development, Offshore Insourcing, Co-Located Roles, Software Product Management, Product Lifecycle

\section{Introduction}

Since the last two decades or so, Global Software Product industry has embraced internationalisation in terms of marketing and

\footnotetext{
* Doctoral Research Scholar, Pondicherry University, India; umashankar6@gmail.com

† Pondicherry University, India; victor.dms@pondiuni.edu.in
} 
developing the software. Global Software Development (GSD), Distributed Development and Offshoring are few terms that are used in conjunction with the process of developing the software across the globe. GSD as a practice applies to both software projects/services as well as software products. While many of the business drivers, benefits, issues, and challenges associated with GSD are common for the development of both services and products, there also are unique factors that would apply to each. This study would focus only on those with respect software products.

Previous literature records the benefits of GSD that are realised at the business levels as well as at organisational, team and at process or task levels. Studies have been conducted to evaluate the extent to which the projected benefits were realised, the causes of failure and challenges involved in implementing GSD. This has facilitated in identifying the key success factors and solutions to address these challenges.

While the ability to work across various time zones was seen as one of the merits of GSD, it in turn led to issues related to knowledge transfer effectiveness, communication and coordination amongst teams, roles and business functions that were spread out across the global locations apart from cultural diversity which has been cited in prior literature as another dimension that influences the functionalities of GSD.

Prior to GSD becoming a popular practice in software companies, the conventional approach has been to co-locate most of the business roles and functions in one-site which was also close to major markets of their products. Many of the issues of GSD noted earlier evolved since the roles had to be distributed across the global locations.

Based on published literature, this study explores the benefit of colocating some of the key roles along with software development at offshore locations and thus attempting to address the challenges that arise out of distributed software development. The successful implementation of GSD could favor the product's wider reach to markets with speed and thus impact the product life-cycle. 
This paper is organised in the following way. Section 2 gives an overview of the evolution of GSD and clarifies various related terminologies. Sections 3 through 7 reviews the business drivers and benefits of GSD; the extent to which these benefits have been realised; various issues and success factors of GSD as identified in the literature; solutions cited to overcome those challenges; the role of co-located key roles at offshore locations as a possible solution in addressing these challenges and the impact it could have on the Product Lifecycle. Section 8 summarises the inferences and presents suggestions for further research in the domain.

\section{Evolution of Offshoring and GSD and explanation of related terminologies}

Davis, Ein-Dor, King and Torkzadeh (2006) define Offshoring as "provision of organizational products and services from locations in other countries."

As per Rönkkö, Eloranta, Mustaniemi, Mutanen, and Kontio (2007), Global Software Development (GSD) or Distributed Software Development is typically a practice that is connected to the two offshoring strategies, namely Offshore Outsourcing and Offshore insourcing. This study is related to the latter - that is, offshore in sourcing (contracting with a wholly owned subsidiary in another country). Avram (2007) defines GSD as, "Software development that is geographically, remotely or globally distributed with the aim of rationalizing the development process and products."

While Offshoring as a practice emerged and evolved since the 1970s across industries, it gained momentum in the IT/ Software industry since the 1990s due to three factors - higher demand due to factors like $\mathrm{Y} 2 \mathrm{k}$, higher supply due to low cost and emergence of skilled labor in developing countries and advances in ICT industry and infrastructure investments by host countries, as per Lewin and Peeters (2006).

The following sections would quote the term GSD commonly that is synonymous with GPD (Global Product Development), international product transfer and Off-shore insourcing of Software products. 


\section{The business drivers and benefits of GSD}

As quoted by Stephan and Silvia (2008) on the Offshoring Research Network (ORN), "Survey findings, growth strategy, competitive pressure, improved service levels and business process redesign (Figure 1) were the strategic drivers of GSD in addition to reduced labour cost and access to skilled resources".

The benefits of GSD go beyond though. As per Ågerfalk, Fitzgerald, Holmstrom and Conchúir (2008), GSD's benefits encompass organisational, team and process levels. While some of these benefits such as proximity and speed to market are well known, there are also less familiar benefits like innovation, shared business practices, improved resource allocation at organization level; at team and process levels the benefits include task modularisation and improved team autonomy.

The Product Lifecycle theory referred to by Kotler, Armstrong, Franke and Bunn (1990) typically relates the sales of products over time with some of the strategic sales drivers such as speed to market, growth strategy and access to new markets directly related to Offshoring. One could associate GSD's successful implementation to the drivers of product life-cycle.

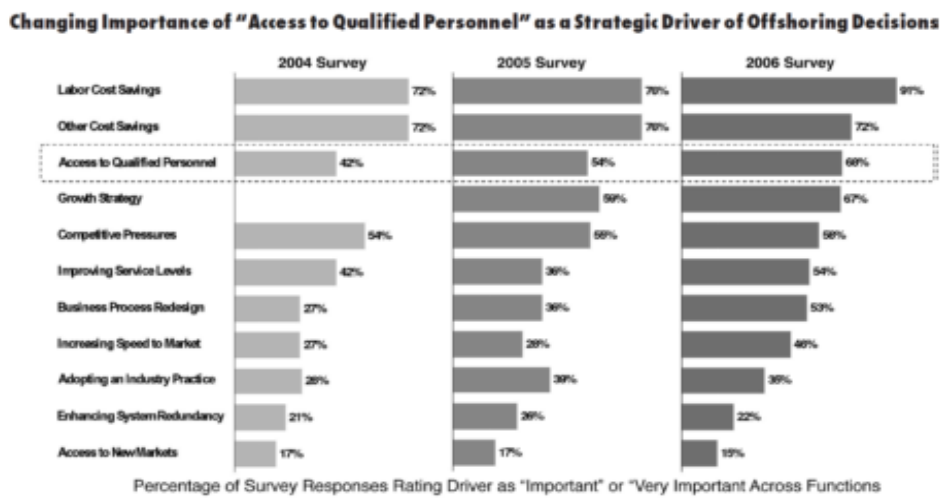

Fig 1 Business drivers of Offshoring (Source: Duke University/ Archstone Consulting Offshore Research Network 2004 and 2005 U.S. Surveys and Duke University/ Booz Allen Hamilton Offshore Research Network 2006 U.S. Survey): Reprinted from “A dynamic perspective on next-generation Offshoring: The global sourcing of science and engineering talent”. Stephan, M., Silvia, M., \& Arie Y, L., 2008, Academy of Management Perspectives, 22(3), 35-54. 


\section{The extent of realisation of GSD's benefits}

Although the practice of GSD projects these benefits, the extant literature also records the degree to which these benefits were realized. A multi-case study done by Conchúir, Holmstrom, Agerfalk and Fitzgerald (2006) at three MNCs that have extensive experience in GSD concludes that the benefits are neither clear-cut nor could be taken for granted. The study posits that the benefit of reduced development cost is only partially realised owing to high overhead in communication and coordination efforts. Also, it was noted that leveraging time-zone effectiveness did not find takers for development roles but only for roles like testing.

The systematic literature review undertaken by Šmite, Wohlin, Gorschek and Feldt (2010) records that more than half of the reported cases in the literature on GSD have reported problems; only about $35 \%$ of them reported successful practices or are success stories.

\section{Issues of GSD and its success factors}

In a combined literature review and interview done by Lamersdorf and Münch (2010), the goals of GSD were mapped to the factors that caused the failure in achieving the goals - namely problems in Communication, Coordination, Knowledge Management and Process maturity among others.

A case study was done by Herbsleb, Paulish and Bass (2005) at Siemens involving software development at nine different locations listed communication, process maturity and domain knowledge as the causes that created various issues among few others. In a largescale survey done with engineers at Microsoft Corporation, it was found that communication and coordination reported the highest issues in GSD as reported by Begel and Nagappan (2008).

In a case study done by Damian and Zowghi (2002), focusing on Requirements Engineering Function, Communication Efficiency and Knowledge Management were listed as important success factors of GSD in addition to a few others. The same is reciprocated by Sudhakar (2013) that communication and knowledge transfer were among the top 6 most important success factors of GSD 
among a total of 75 , in a systematic literature review undertaken by him.

A gap witnessed in most of the studies is that the GSD issues that are unique to software product development as compared to software services were not explicitly identified.

\section{Solutions to overcome key issues of GSD}

GSD is a reality. In their large-scale survey done at Microsoft Corporation, Begel and Nagappan (2008) observed that more than $50 \%$ of the respondents regularly collaborate with global stakeholders that are more than three time zones away. Studies have recommended solutions to address some of the issues in GSD implementation discussed above and pave way for GSD's success.

Processes involving effective communication, coordination and knowledge acquisition could help stakeholders across multi-sites to have shared understanding during Requirements Engineering phase of software development life cycle, as studied by Damian (2007). The study further clarifies that defining a clear organisational structure and creating roles and assigning the right responsibilities could be considered as strategies to alleviate these challenges.

Khanna (2014) cites that providing authority and freedom to the management at the Offshore locations as one of the key approaches to resolve the talent management challenges faced at these global locations. He suggests that the authority and responsibilities of the various roles at these locations need to be in line with the strengths of these locations.

In the next section, we explore the import of placing the right roles at global locations as one of the solutions in addressing the key challenges in a GSD set up.

\section{Co-located key roles at global locations with Software Development}

Prior to GSD's evolution, roles that were associated with the software development life cycle were based in one location and 
hence many of the issues caused due to distributed development did not apply in the conventional approach.

The practice of GSD involved in moving software development projects had maximal benefits in terms of labor cost savings and skilled pool availability. Strategic and key roles such as Business Analysts, Product Management, or Product Support typically involved a lesser number of people as compared to Software Development and hence movement of those roles to Offshore was neither pursued actively nor did they follow any structured or planned approach. Most GSD implementations focused Offshoring the software development roles in isolation without the adjacent roles and it possibly led to the eroding the merits of co-located software making and thereby led to many of the issues listed earlier.

There is a research gap that needs to be highlighted. Not much research is available to study the drivers and effects when other roles listed above were Offshored as compared to what was published on software development Offshoring.

In the following sections, literature that relates to co-locating key roles at global locations have been reviewed; such an approach would lead to having a better understanding the business benefits of GSD and yet be able to combine the merits of co-located business roles and functions.

Lane and Agerfalk (2008) in their study, analyse the impact on project deliverables with respect to the placement of various roles in a GSD set up. They cite that when the product designers and development-support personnel were centrally placed to be accessed by remote stakeholders, it led to coordination issues. When business analysts' roles were remotely located, there were communication issues too.

On the other hand, Botzenhardt, Meth and Maedche (2011) in their empirical study, establish that cross-functional integration across Product Management and Product development roles positively affect the product release's success. This supports the argument of their co-location. 
Similarly, g Yan (2004) talks of software maintenance support offered from Offshore locations and improving efficiency. The study was done based on a case study at an actual project.

Going beyond the software product development, a case study done on another hi-tech industry connected to data storage on the international product transfer from the USA to an Asian country, talk about the role of co-located key functions at offshore locations enabling addressing communication and co-ordination issues. This study was done by Terwiesch, Bohn and Chea (2001).

Finally, we looked at the maturation of offshore sourcing of IT software products development in the SITO model. Carmel and Agarwal (2006) asserts that the $4^{\text {th }}$ and final stage in the maturity cycle is called proactive strategic focus. At this stage, global sourcing centres would be performing core corporate activities including new product development, innovations that lead to global growth; the offshore centres would house people with domain expertise. This theory justifies that matured offshore practice would need to transition and co-locate strategic roles at offshore centres.

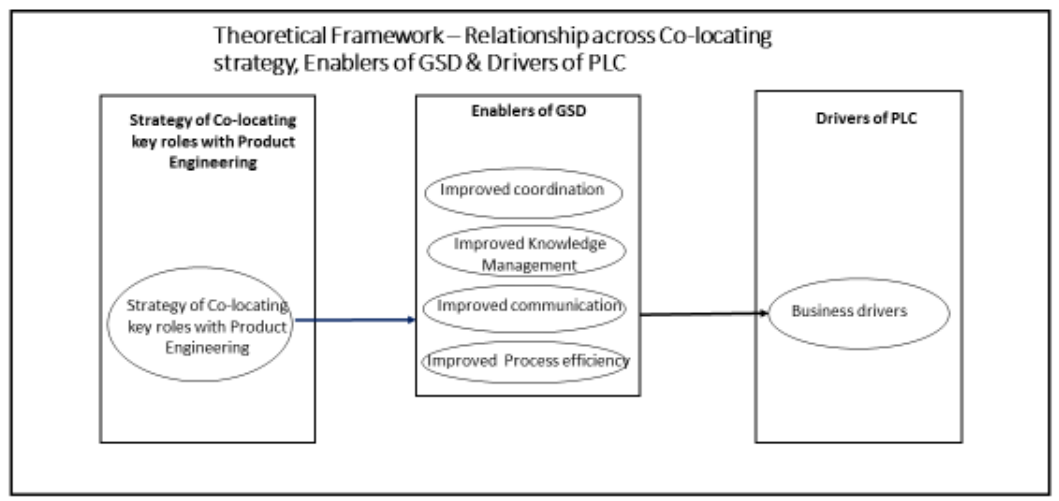

Fig 2 Theoretical framework depicting relationship across co-location strategy, enablers of GSD and business drivers of Product Life-cycle.

Drawing from the above discussion, it could be argued that transitioning key roles such as Product Management and Product Support in addition to and relation to Software Development/ Engineering could address some of the key challenges like communication and coordination issues, knowledge management 
and process maturity involved in GSD. As discussed earlier, successful offshoring and GSD could influence the business drivers of the software products and this, in turn, could influence the drivers of product life-cycle. Figure-2 shows the conceptual framework that depicts this relationship across co-location strategy, enabling successful implementation of GSD and business drivers of the software product and its lifecycle.

The literature hitherto does not discuss clearly the results when the key roles mentioned earlier are co-located with software development. This topic, therefore, requires detailed study and empirical validation.

\section{Conclusion}

Global Software Development is more than a two decades' old practice. There are business benefits realised by providing access to wider markets, speed to market and level playing field with competition among others. The practice though has implementation challenges and issues related to Communication, Coordination Issues, Process Maturity, Knowledge Management and Time- Zone and Cultural Differences.

Several studies have been published in identifying and listing these challenges and also solutions to address them. This study has derived a strategy by which co-locating some of the key roles in addition to software development at the global locations could help software products reap the benefits of both the conventional, preGSD approach as well as that of the current models of GSD. Successful implementation of GSD could, in turn, have a positive impact on the drivers of software product life-cycle. This study cites the relevant literature on this proposition and identifies gaps in literature on GSD implementation specifically in the software product companies. Also, most of the research is limited to addressing issues connected to globalisation of software development roles and not much on other strategic roles like product management or product support and on the effects of colocating the roles at offshore locations.

This, in turn, gives scope for further research opportunities with respect to empirically validating and systematically investigating 
the impact and benefits of co-locating key roles along with software development at offshore locations and thus its impact on the software product life cycle.

\section{References}

Ågerfalk, P. J., Fitzgerald, B., Olsson, H. H., \& Conchúir, E. Ó. (2008, May). Benefits of global software development: the known and unknown. In International Conference on Software Process (pp. 1-9). Springer, Berlin, Heidelber.

Avram, G. (2007). Knowledge work practices in global software development. In Proceedings of the 8th European Conference on Knowledge Management (pp. 87-95).

Begel, A., \& Nagappan, N. (2008, August). Global software development: Who does it? In Global Software Engineering, 2008. ICGSE 2008. IEEE International Conference on (pp. 195-199). IEEE.

Botzenhardt, A., Meth, H., \& Maedche, A. (2011). Cross-functional integration of product management and product design in application software development: exploration of success factors. In Thirty Second International Conference on Information Systems, Shanghai 2011, 1-18. Retrieved from https://ub-madoc.bib.uni-mannheim.de/ 29687/1/ Cross-Functional_Integration_ of_Product_ Management _and_ Product_De.pdf

Carmel, E., \& Agarwal, R. (2006). The maturation of offshore sourcing of information technology work. Information systems outsourcing, 631-650.

Conchúir, E. Ó., Holmstrom, H., Agerfalk, J., \& Fitzgerald, B. (2006, October). Exploring the assumed benefits of global software development. In Global Software Engineering, 2006. ICGSE'06. International Conference on (pp. 159-168). IEEE.

Damian, D. E., \& Zowghi, D. (2002, September). The impact of stakeholders' geographical distribution on managing requirements in a multi-site organization. In Requirements Engineering, 2002. Proceedings. IEEE Joint International Conference on (pp. 319-328). IEEE.

Davis, G., Ein-Dor, P., R King, W., \& Torkzadeh, R. (2006). IT offshoring: History, prospects and challenges. Journal of the Association for Information Systems, 7(11), 770-795.

g Yan, Z. (2004). Efficient Maintenance Support in Offshore Software Development: a Case Study on a Global E-Commerce Project. In 26th International Conference on Software Engineering - W12S Workshop "Third International Workshop on Global Software Development, 12 - 17. 
Herbsleb, J. D., Paulish, D. J., \& Bass, M. (2005, May). Global software development at siemens: experience from nine projects. In Software Engineering, 2005. ICSE 2005. Proceedings. 27th International Conference on (pp. 524-533). IEEE.

Khanna, V. K. (2014). Managing talent in offshore development centres. Paper presented at PMI ${ }^{\circledR}$ Global Congress 2014-EMEA, Dubai, United Arab Emirates. Newtown Square, PA: Project Management Institute.

Kotler, P., Armstrong, G., Franke, G., \& Bunn, M. D. (1990). Marketing: an introduction (Vol. 1). Prentice-Hall.

Lamersdorf, A., \& Münch, J. (2010). Studying the impact of global software development characteristics on project goals: a causal model. Open Software Engineering Journal, 4(1), 2-1.

Lane, M. T., \& Agerfalk, J. (2008, August). On the suitability of particular software development roles to global software development. In Global Software Engineering, 2008. ICGSE 2008. IEEE International Conference on (pp. 3-12). IEEE.

Lewin, A. Y., \& Peeters, C. (2006). Offshoring work: business hype or the onset of fundamental transformation?. Long Range Planning, 39(3), 221239.

Rönkkö, M., Eloranta, E., Mustaniemi, H., Mutanen, O. P., \& Kontio, J. (2007). Finnish software product business: Results of the national software industry survey 2007. Helsinki University of Technology, Software Business Laboratory. Retrieved from http://users.jyu.fi/ حluomae/softwareindustrysurvey/Publications/Report_2007.pdf

Šmite, D., Wohlin, C., Gorschek, T., \& Feldt, R. (2010). Empirical evidence in global software engineering: a systematic review. Empirical software engineering, 15(1), 91-118.

Stephan, M., \& Silvia, M. (2008). A dynamic perspective on nextgeneration offshoring: The global sourcing of science and engineering talent. The Academy of Management Perspectives, 22(3), 35-54.

Sudhakar, G. P. (2013). A review of critical success factors for offshore software development projects. Organizacija, 46(6), 282-296.

Terwiesch, C., Bohn, R., \& Chea, K. (2001). International product transfer and production ramp-up: a case study from the data storage industry. RED Management, 31(4), 435-451. 